\title{
LincRNAFEZF1-AS1 represses p21 expression to promote gastric cancer proliferation through LSD1-Mediated H3K4me2 demethylation
}

Yan-wen Liu' ${ }^{1}$, Rui Xia ${ }^{2}$, Kai $\mathrm{Lu}^{3}$, Min Xie ${ }^{4}$, Fen Yang ${ }^{4}$, Ming Sun ${ }^{4}$, Wei De ${ }^{4^{*}}$, Cailian Wang ${ }^{1^{*}}$ and Guozhong $\mathrm{Ji}^{5^{*}}$

\begin{abstract}
Background: Although the prognosis of gastric cancer patients have a favorable progression, there are some patients with unusual patterns of locoregional and systemic recurrence. Therefore, a better understanding of early molecular events of the disease is needed. Current evidences demonstrate that long noncoding RNAs (IncRNAs) may be an important class of functional regulators involved in human gastric cancers development. Our previous studies suggest that HOTAIR contributes to gastric cancer development, and the overexpression of HOTAIR predicts a poor prognosis. In this study, we investigated the characteristic of the LncRNA FEZF1-AS1 in gastric cancer.

Methods: QRT-PCR was used to detect the expression of FEZF1-AS1 in gastric cancer tissues and cells. MTT assays, clonogenic survival assays and nude mouse xenograft model were used to examine the tumorigenesis function of FEZF1-AS1 in vitro and in vivo. Bioinformatics analysis were used to select downstream target genes of FEZF1-AS1. Cell cycle analysis, ChIP, RIP,RNA Pulldown assays were examined to dissect molecular mechanisms.

Results: In this study, we reported that FEZF1-AS1, a 2564 bp RNA, was overexpressed in gastric cancer, and upregulated FEZF1-AS1 expression indicated larger tumor size and higher clinical stage; additional higher expression of FEZF1-AS1 predicted poor prognosis. Further experiments revealed that knockdown FEZF1-AS1 significantly inhibited gastric cancer cells proliferation by inducing G1 arrest and apoptosis, whereas endogenous expression FEZF1-AS1 promoted cell growth. Additionally, RIP assay and RNA-pulldown assay evidenced that FEZF1-AS1 could epigenetically repress the expression of P21 via binding with LSD1, the first discovered demethylase. ChIP assays demonstrated that LSD1 could directly bind to the promoter of P21, inducing H3K4me2 demethylation.

Conclusion: In summary, these data demonstrated that FEZF1-AS1 could act as an "oncogene" for gastric cancer partly through suppressing P21 expression; FEZF1-AS1 may be served as a candidate prognostic biomarker and target for new therapies of gastric cancer patients.
\end{abstract}

Keywords: FEZF1-AS1, LSD1, H3K4me2, P21, Gastric cancer

\footnotetext{
*Correspondence: lyw0171@outlook.com; wangcailian65@hotmail.com; nyefygz@163.com

Yan-wen Liu was the first author

${ }^{4}$ Department of Biochemistry and Molecular Biology, Nanjing Medical

University, Nanjing, Jiangsu, People's Republic of China

'Department of Oncology, Zhongda Hospital, Medical School, Southeast

University, Nanjing, Jiangsu, People's Republic of China

${ }^{5}$ Department of Gastroenterology Second Affiliated Hospital of Nanjing

Medical University, Nanjing, Jiangsu, People's Republic of China

Full list of author information is available at the end of the article
}

Biomed Central

(c) The Author(s). 2017 Open Access This article is distributed under the terms of the Creative Commons Attribution 4.0 International License (http://creativecommons.org/licenses/by/4.0/), which permits unrestricted use, distribution, and reproduction in any medium, provided you give appropriate credit to the original author(s) and the source, provide a link to the Creative Commons license, and indicate if changes were made. The Creative Commons Public Domain Dedication waiver (http://creativecommons.org/publicdomain/zero/1.0/) applies to the data made available in this article, unless otherwise stated. 


\section{Background}

Gastric cancer is the third leading cause of cancerrelated deaths worldwide, and the poor prognosis of patients is largely due to the high frequency of tumor recurrence or metastasis within 24 months after surgical resection $[1,2]$. To improve gastric cancer early diagnosis and targeted therapy, a better understanding of early molecular events of the disease is warranted. Cell proliferation is a pivotal characteristic of malignancy and a hallmark cancer capability [3]. Dysregulation of all cycle is a vital reason for tumor cell proliferation. Moreover, the cell cycle regulation has come to be a promising therapeutic target, which suggests that discovery of novel proliferation related genes could lead to improve treatment of cancer $[4,5]$.

Recent integrative genomic studies have revealed that $98 \%$ of the human genome transcripts are non-coding RNA (ncRNA) with limited or no protein-coding capacity [6-8]. Long non-coding RNAs (lncRNAs), greater than 200 nt are important new members of the ncRNA family [9]. Researchers have demonstrated that the aberrant lncRNAs expression involve in diverse human diseases, in particular cancers [10-12]. Such one is HOTAIR, lots of studies have shown that HOTAIR is overexpressed in colorectal cancer, pancreatic cancer, breast cancer, gastric cancer and gastrointestinal stromal tumors and is positively correlated with a poor clinical outcome [13-16]. Furthermore, lncRNA regulate drug resistance, for instance, H19 epigenetically inducted MDR1-associated drug resistance in human hepatocellular carcinoma cells [17]. Recently, a study showed that nearly $76 \%$ of the GENCODE annotated lncRNAs was differentially expressed between gastric cancer and normal gastric tissue [18]; for example, HOTAIR and HOXA-AS2 were overexpressed in gastric cancer and indicated poor prognosis; however, a large number of lncRNAs have been uncharacterized [19-22].

Recently, mounting evidences showed that some lncRNAs epigenetically regulate gene expression by DNA methylation and histone modifications, which contain methylation, acetylation, phosphorylation et al. [23]. Histone methylation is Histone $\mathrm{H} 3 / \mathrm{H} 4$ on lysine different sites methylation or demethylation, which is regulated by histone methylases or demethylases. HOTAIR and ANRIL etc. could recruit and bind with the Polycomb complex PRC2 (EZH2, SUZ12 and EED), which enhances histone H3lysine-27 trimethylation, affecting chromatin compression tightness in suppressing gene expression [15, 24]. Lysine-specific demethylase 1(LSD1) is the first discovered demethylase, which demethylates mono- and dimethylated residues of lysine-4 on histone $\mathrm{H} 3$ (H3K4me1, $\mathrm{H} 3 \mathrm{~K} 4 \mathrm{me} 2$ orH3K9me1) and results in transcriptional repression $[25,26]$. In addition, LSD1 also activates transcription through demethylation of H3K9me2 [27]. LSD1 is pivotal for mammalian tumorigenicity and progression in many type of cancers, moreover, LSD1 overexpression predict poor prognosis and aggressive tumor biology [28-31]. Many studies had shown LSD1 epigenetically regulate cell cycle related gene expression to affect G1/S phase arrest, contributing to cell proliferation [32-34].

FEZF1-AS1 is an lncRNA producing a 2564 bp transcript, located in chromosome 7 . In this study, we demonstrated that FEZF1-AS1 was overexpressed in the tumor tissues than the paracancerous tissues; furthermore, overexpression of FEZF1-AS1 was observed in larger tumors, advanced gastric cancer and predicted poor DFS. Additional experiments revealed that FEZF1AS1 knockdown significantly repressed proliferation both in vitro and vivo, and inhibited cells cycle progression by causing G1/S arrest. In addition, FEZF1-AS1 also recruited and bound to LSD1 to epigenetically repress downstream gene $\mathrm{p} 21$, thereby promoting proliferation in advanced stages of gastric cancer. By these efforts, we aim to propose a model for FEZF1-AS1-mediated cell proliferation in gastric cancer.

\section{Methods}

\section{Tissue samples}

In this study, matched tumor tissues and adjacent nontumor tissues were obtained from 82 gastric cancer patients at the Department of Surgical Oncology Jiangsu Province People's Hospital, Nanjing Medical University from March 2011 to December 2011. Two pathologists evaluated all specimens according to the World Health Organization (WHO) guidelines and the pTNM Union for International Cancer Control (UICC) pathological staging criteria. No local or systemic treatments were administered to these patients before surgery. The tissues were immediately frozen in liquid nitrogen and stored at $-80{ }^{\circ} \mathrm{C}$ until use. Informed consent was obtained from all patients. The Human Research Ethics Committee of Jiangsu Province People's Hospital approved the study.

\section{Total RNA extraction Quantitative real-time polymerase chain reaction}

Total RNA was extracted from the cultured cells and frozen tissues using TRIzol reagent (Invitrogen, Karlsruhe, Germany) following the manufacturer's protocol. Quantitative real-time polymerase chain reaction (PCR) was performed to detect FEZF1-AS1 and P21 using the PrimeScript RT Reagent Kit and SYBR Premix Ex Taq (TaKaRa, Dalian, China) according to the manufacturer's instructions. The results were normalized to the expression of glyceraldehyde-3-phosphate dehydrogenase (GAPDH). The specific primers used are presented in Additional file 1: Table S1. The qPCR results were analyzed and expressed relative to the CT (threshold cycle) values 
and then converted to fold changes.2.0-fold change was considered significant.

\section{Plasmid generation}

The FEZF1-AS1 sequence was synthesized and subcloned into the pCDNA3.1 (Invitrogen, Shanghai, China) vector. Ectopic expression of FEZF1-AS1 was achieved via pCDNA-FEZF1-AS1 transfection, with an empty pCDNA3.1 vector used as a control. We also synthesised shRNA sequence targeted FEZF1-AS1. Si-FEZF1-AS1 sequence removed five bases of the 3 'end were converted to sh-FEZF1-AS1. After annealing of the complementary shRNA oligonucleotides, we cloned the annealed oligonucleotides into pENTR vector (sh-FEZF1-AS1) (Additional file 1: Table S1). The expression levels of FEZF1-AS1 were detected by qPCR.

\section{Cell culture}

The MGC-803 lines were cultured in RPMI 1640 medium containing $10 \%$ fetal bovine serum and incubated at $37^{\circ} \mathrm{C}$, $5 \% \mathrm{CO}_{2}$, and saturated humidity. The SGC-7901 cells were cultured in DMEM medium containing 10\% fetal bovine serum and incubated at $37{ }^{\circ} \mathrm{C}, 5 \% \mathrm{CO} 2$, and saturated humidity. The AGS lines were cultured in F 12 medium containing $10 \%$ fetal bovine serum and incubated at $37{ }^{\circ} \mathrm{C}, 5 \% \mathrm{CO}_{2}$, and saturated humidity. Cell growth was observed under an inverted microscope. Cells in the logarithmic growth phase were harvested for the experiments.

\section{Cell transfection}

Plasmid vectors (pCDNA3.1-FEZF1-AS1 and pCDNA3.1) for transfection were prepared using DNA Midiprep or Midiprep kits (Qiagen, Hilden, Germany) and transfected into MGC-803cells. The si-FEZF1-AS1, sh-FEZF1-AS1, si-LSD1 or si-NC was transfected into AGS and SGC7901 cells (Additional file 1: Table S1).

\section{Cell cycle and apoptosis analysis}

AGS and SGC-7901cells transiently transfected with si-FEZF1-AS1 or si-NC and MGC-803 transfected with pcDNA-FEZF1-AS1 or pcDNA-3.1, cells were analyzed by flow cytometry (FACScan; BD Biosciences) using CellQuest software (BD Biosciences).

\section{MTT assay and clone formation}

MTT assay and clone formation were used for evaluated cell viability and proliferation. Cell proliferation was documented following the manufacturer's protocol every $24 \mathrm{~h}$. For the colony formation assay, cells were seeded in a fresh six-well plate and maintained in media containing $10 \% \mathrm{FBS}$, replacing the medium every 4 days. After 14 days, methanol and stained with $0.1 \%$ crystal violet (Sigma-Aldrich) fixed cells and count clones.

\section{Tumor formation assay in a nude mouse model}

The male athymic BALB/c nude mice aged 5 weeks were maintained under specific pathogen-free conditions and manipulated according to protocols approved by the Shanghai Medical Experimental Animal Care Commission. A volume of $0.1 \mathrm{ml}$ of suspended cells with sh-FEZF1-AS1 and pENTR vector (EV) was respectively subcutaneously injected into the posterior flank of each mouse. At 15 days post-injection, mice were euthanized and the primary tumors were excised, paraffinembedded, formal infixed and performed H\&E staining, immunostaining analysis for Ki-67 protein expression.

\section{Western blotting analysis and antibodies}

Cell lysates were prepared using RIPA protein extraction reagent (Beyotime, Beijing, China) supplemented with a protease inhibitor cocktail (Roche, CA, USA) and phenylmethylsulfonyl fluoride (Roche). GAPDH was used as a control. Antibodies (1:1000) against cyclin D1, CDK2, CDK4, CDK6 and P21were purchased from Abcam.

\section{Subcellular fractionation location}

The separation of nuclear and cytosolic fractions was performed using the PARIS Kit (Life Technologies) according to the manufacturer's instructions.

\section{Chromatin immunoprecipitation (ChIP)}

We performed chromatin immunoprecipitation (ChIP) using the EZ ChIP ${ }^{\mathrm{rm}}$ Chromatin Immunoprecipitation Kit for cell line samples (Millipore, Bedford, MA). Briefly, we sonicated the crosslinked chromatin DNA into 200to 500-bp fragments. The chromatin was then immunoprecipitated using an anti-demethyl-histone $\mathrm{H} 3$ antibody and LSD1 (1:1000). Normal mouse IgG was used as the negative control. The primer sequences are listed in Additional file 1: Table S1. The antibodies for the ChIP assays of LSD1, H3K4 and H3K9 were obtained from Millipore. Quantification of the immunoprecipitated DNA was performed using qPCR with SYBR Green Mix (Takara). The ChIP data were calculated as a percentage relative to the input DNA using the equation 2[Input Ct- Target Ct] $\times 0.1 \times 100$.

\section{RNA immunoprecipitation(RIP)}

We performed RNA immunoprecipitation (RIP) experiments using the Magna RIP ${ }^{\mathrm{rm}}$ RNA-Binding Protein Immunoprecipitation Kit (Millipore, USA) according to the manufacturer's instructions. The antibodies for the RIP assays of LSD1 were obtained from Abcam. The co-precipitated RNAs were detected by reversetranscription PCR. The total RNAs were the input controls. 


\section{RNA pulldown assay}

Biotin-labeled RNAs were transcribed in vitro with the Biotin RNA Labeling Mix (Roche Diagnostics) and T7 RNA polymerase (Roche Diagnostics), treated with RNase-free DNase I (Roche), and purified with an RNeasy Mini Kit (Qiagen, Valencia, CA). Next, $1 \mathrm{mg}$ whole-cell lysates from SGC7901 cells was incubated with $3 \mu \mathrm{g}$ of purified biotinylated transcripts for $1 \mathrm{~h}$ at $25{ }^{\circ} \mathrm{C}$. Complexes were isolated with streptavidin agarose beads (Invitrogen). The beads were washed briefly three times and boiled in sodium dodecyl sulfate (SDS) buffer, and the retrieved protein was detected using the standard western blot technique.

\section{Bioinformatics methods}

Gene set enrichment analysis (GSEA) software was downloaded from Broad Institute (http://www.broadinstitute.org/gsea/index.jsp). Gene profiling data downstream FEZF1-AS1 were obtained from Gene Expression Omnibus (GEO) site (http://www.ncbi.nlm.nih.gov/geo/ query/acc.cgi?acc $=$ GSE53137). Significantly enriched gene sets were identified, which produced a nominal $P$-value 0.05. UCSC Genome Browser (http://genome.ucsc.edu/cgibin/hgGateway) was used to analyze promoter regions.

\section{Statistical analysis}

The SPSS 17.0 statistical analysis software was used for the statistical analysis of the experimental data. The significance of differences between groups was estimated by Student's t-test. The levels of FEZF1-AS1 in the gastric cancer patients were compared using the MannWhitney $U$ test. The disease-free survival probability was analyzed using Kaplan-Meier methods and evaluated using the log-rank test. A $p$ value less than 0.05 were considered significant.

\section{Results}

\section{FEZF1-AS1 expression levels in human gastric cancer} tissue

To explore the function of LncRNAs in gastric cancer, firstly, we profiled the expression levels of LncRNAs in human gastric cancer tissues and normal tissue by using raw microarray data downloaded from GEO (GSE53137) [35] and mapsoft (http://lncrnamap.mbc.nctu.edu.tw/ php/search.php). The results show that FEZF1-AS1 expression level is upregulated in gastric cancerous tissues compared with noncancerous tissues (42.64 Fold, Fig. 1a); furthermore, FEZF1-AS1 expression is also overexpressed in gastric cancer tissues (GSE58828)(23.67 Fold, Fig. 1b). Next, we used qRT-PCR to detect FEZF1-AS1 expression in 82 paired gastric cancer samples and adjacent histologically normal tissues. FEZF1-AS1 expression was significantly overexpressed in the gastric cancer $(p=0.0001)$ compared to the adjacent histologically normal tissues (Fig. 1c). Furthermore, receiver operating characteristic (ROC) curves were determined to evaluate the sensitivity and specificity of FEZF1-AS1 expression in predicting gastric cancer tissues from normal tissues. Notably, FEZF1AS1dayisplayed predictive, with an area under curve (AUC) of $0.631(P=0.049$, Fig. 1d). These results implied that FEZF1-AS1might act as "oncogene" to promote the progression of gastric cancer and might provide imperative clinical significance in gastric cancer diagnosis.

FEZF1-AS1 upregulation associated with tumor size, stage and poor survival of gastric cancer patients

To assess whether FEZF1-AS1expression was correlated with clinical pathological parameters and prognosis of gastric cancer, according to relative FEZF1-AS1 expression in tumor tissues, the 82 gastric patients were classified into two groups: the high FEZF1-AS1 group ( $n=$ 52 , fold-change $\geq 2)$; and the low FEZF1-AS1 group $(n=30$, fold-change $<2$ ) (Fig. 2a). The clinical pathology parameters of 82 gastric carcinoma patients were shown in Table 1 . Noticeably, high FEZF1-AS1 expression in gastric cancer was significantly correlated with tumor size and advanced TNM stage (Fig. 2b and c). For disease-free survival patients with high FEZF1-AS1 expression had a significantly poorer prognosis than those with low FEZF1-AS1 expression in gastric cancer patients $(P<0.05$, log-rank test; Fig. 2d). Furthermore, ROC curves were determined to evaluate the sensitivity and specificity of the survival prediction based on the FEZF1-AS1 expression. FEZF1-AS1 displayed predictive, with an area under curve (AUC) of $0.56(P=0.019)$ (Fig. 2e). The AJCC TNM staging system has been widely accepted as a powerful predictor of treatment response and survival in gastric cancer, thus it is of interest to test whether the prognostic value of the FEZF1AS1 is independent of AJCC stage. Multivariable Cox regression analysis adjusting AJCC stage and other factors confirmed the association between FEZF1-AS1 expression and shorter survival (hazard ratio (HR), 0.38; 95\% confidence interval (CI), 0.195-0.739; $\mathrm{P}<0.01)$. Collectively, these results indicate that FEZF1-AS1 overexpression play an important role in gastric cancer progression and may be useful for the prognostic or progression markers in gastric cancer.

Modulation of FEZF1-AS1 expression in gastric cancer cells To investigate the effect of FEZF1-AS1on the gastric cancer cells, we firstly examined the endogenous expression levels of FEZF1-AS1 in various cancer cell lines by qRT-PCR. As shown in Additional file 2: Figure S1A, of the five gastric cancer cell lines (SGC- 7901, BGC-823, MGC-803, AGS and HGC-27), SGC-7901 and AGS expressed higher levels of FEZF1-AS1 than the normal gastric epithelium cell line (GES-1); however, BGC-823 and MGC-803 expressed deficiency. Therefore, we chose 


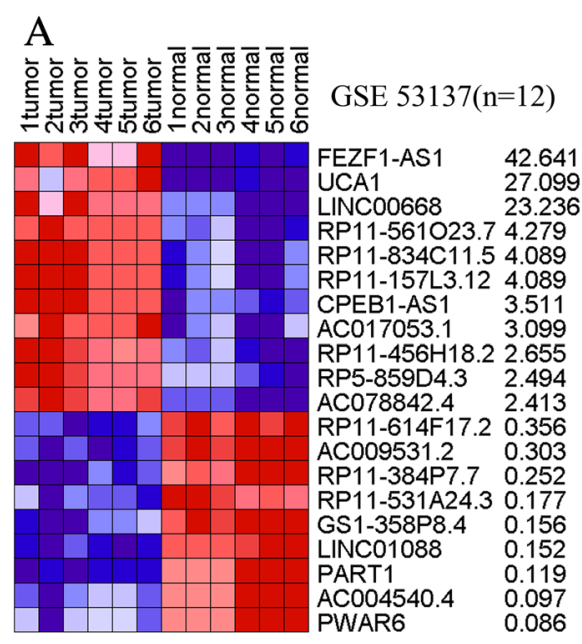

$\mathrm{C}$

Row Z-score of Log2 quantile-normalized signal intensity
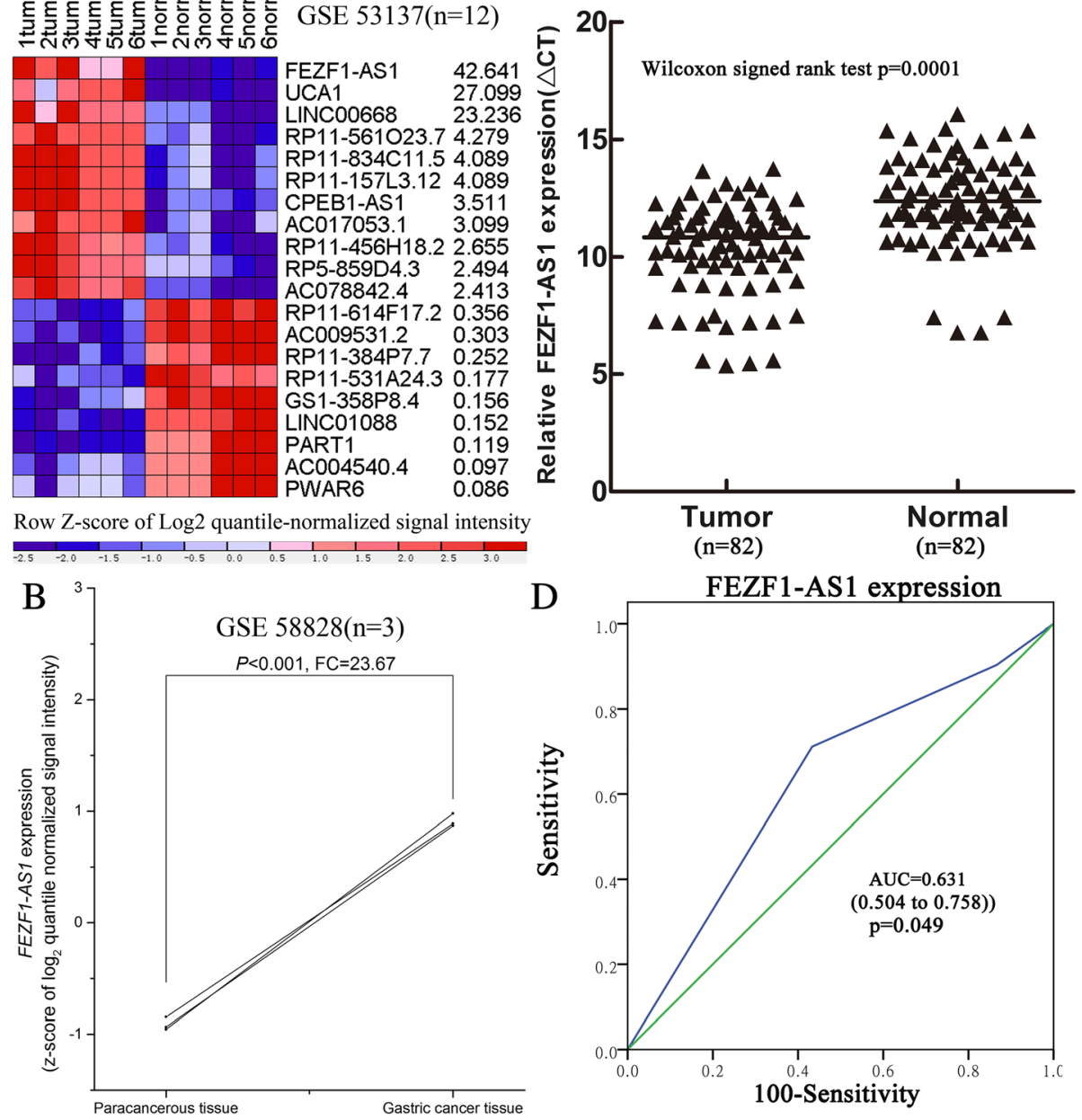

Fig. 1 FEZF1-AS1 expression levels in human gastric cancer tissue. a, b Relative expression levels of FEZF1-AS1 in GEO database. c Relative expression of FEZF1-AS1 in the tumor tissue compared to adjacent normal tissues $(n=82)$. FEZF1-AS1 expression was evaluated by qRT-PCR and normalized to GAPDH expression. $\mathbf{d}$ ROC curve for prediction of gastric cancer based on FEZF1-AS1 expression, using corresponding adjacent normal tissues as a control. ${ }^{*} P<0.05$

SGC-7901 and AGS as loss of function experimental cell lines and MGC-803 as gain of function experimental cell line. The results showed that FEZF1-AS1 expression was effectively knocked down in AGS、SGC-7901and MGC803cells by si-FEZF1-AS11\# + 2\#、 si-FEZF1-AS12\# + 3\# and pcDNA-FEZF1-AS1 (Additional file 2: Figure S1B), which were subsequently used in the further experiments. The efficiency of the sh- FEZF1-AS1、si-LSD1、si-SP1 and pcDNA-SP1 was shown in Additional file 2: Figure $\mathrm{S} 1 \mathrm{C}, \mathrm{D}$ and $\mathrm{E}$.

\section{FEZF1-AS1 promoted gastric cancer cells proliferation in vitro and vivo}

To investigate the effect of FEZF1-AS1on the gastric cancer cells, MTT assays were performed and the results revealed that knockdown of FEZF1-AS1 decreased AGS and SGC-7901 cells proliferation compared with the respective controls, whereas ectopic overexpression FEZF1-AS1 promoted cell growth in MGC-803 (Fig. 3a). Similarly, the results of colony-formation assays revealed that clonogenic survival was significantly decreased following downregulation of FEZF1-AS1 in SGC-7901 and AGS cells, but markedly increased in FEZF1-AS1 overexpression MGC-803 (Fig. 3b). To further investigate the tumorigenesis function of FEZF1-AS1 in vivo, we used nude mouse xenograft model. Sh- FEZF1-AS1 stably transfected SGC-7901 cells were injected subcutaneous of fourteen nude mice respectively. Two weeks later, the mice were sacrificed and the xenografts were collected. As expected, the sh- FEZF1-AS1 group exhibited generally smaller tumors and displayed less weight and volum compared to the pENTR vector group (Fig. 3c). This difference was further confirmed following examination of the xenograft by hematoxylin and eosin 


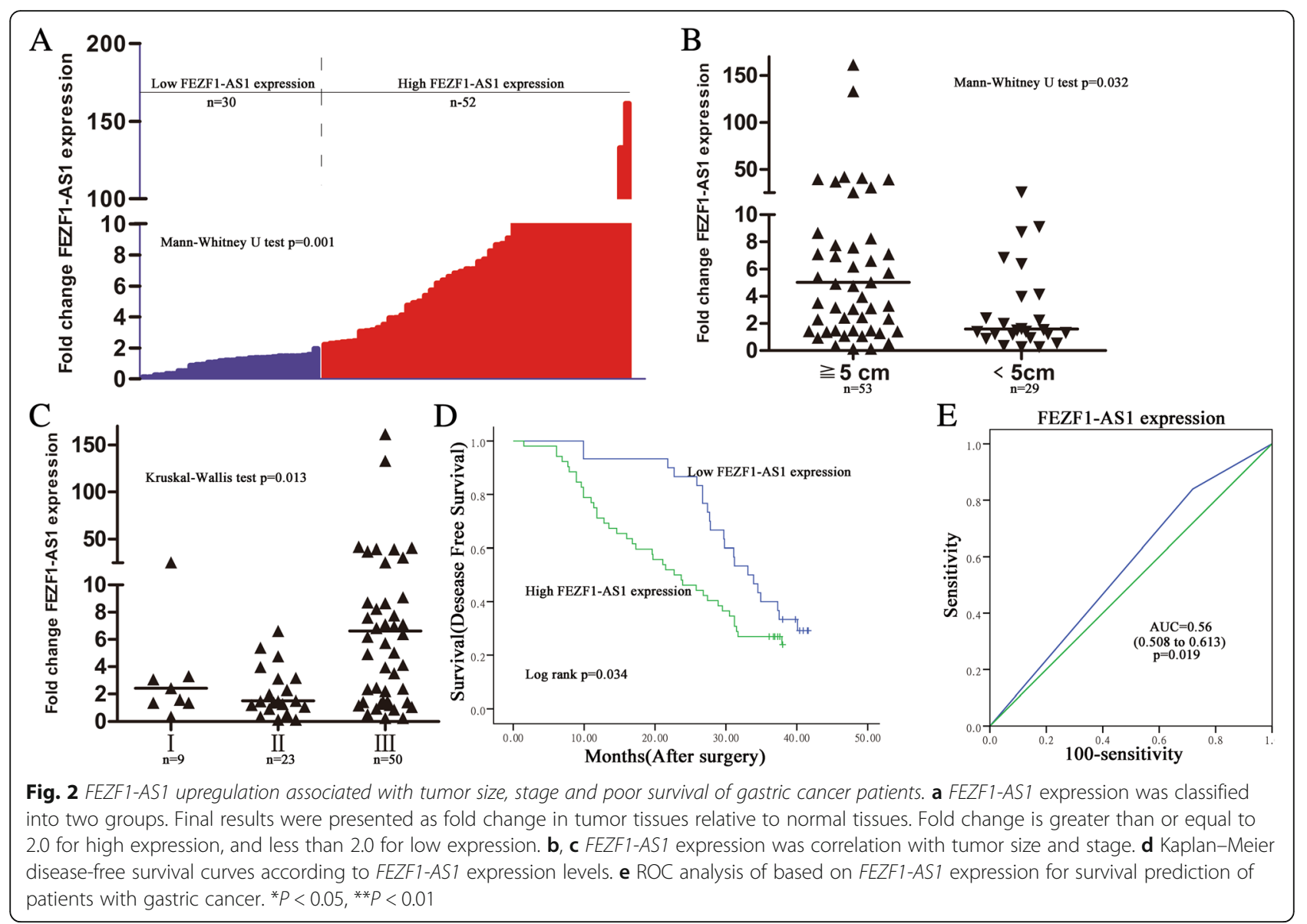

(HE), and the tumors developed from sh-FEZF1-AS1 cells displayed lower Ki-67 staining than control group (Fig. 3d). Taken together, these results indicated that FEZF1-AS1 possessed a vital role for FEZF1-AS1in tumorigenicity and tumor growth of gastric cancer.

\section{FEZF1-AS1 promoted proliferation of gastric cancer cells} by inducing cell-cycle progress and reducing apoptosis in gastric cancer cells

Dysregulation of cell cycle is a vital reason for tumor cell proliferation, to further explore whether FEZF1-AS1 promoted proliferation by regulation cell cycle progression in gastric cancer cell; we examined cell cycle by using flow cytometric analysis. The results revealed that SGC-7901 and AGS cells with si-RNAs had an obvious cell cycle arrest in the G1-S phase and the population of cells in the $\mathrm{S}$ phase was decreased (Fig. 4a and b). However, ectopic expression FEZF1-AS1 induced G1-S progression and accumulated $S$ phase (Fig. 4c). Furthermore, we examined apoptosis rate by using flow cytometric analysis. The results showed that the percentage of early and later apoptotic cells was significantly increased in SGC-7901 and AGS cells with si- FEZF1$A S 1$ than the si-NC cells (Fig 4d and e). Whereas ectopic expression FEZF1-AS1 repressed apoptosis than pcDNA vector (Fig. 4f). Moreover, western blot analysis showed that the protein levels of CyclinD1/CDK2/CDK4/CDK6 were significantly decreased in AGS and SGC-7901cell with si- RNA (Fig 4g and h); the result was conserved in MGC-803cell (Fig. 4i). These results confirmed that FEZF1-AS1 is involved in cell-cycle regulation.

\section{FEZF1-AS1 downregulated P21 expression driving cell cycle}

To investigate whether FEZF1-AS1 could regulate cellcycle, Additional file 3: Figure S2A illustrates plots from gene set enrichment analysis (GSEA) using gastric cancer patient gene profiling data (GSE53137) showing that gene set differences in FEZF1-AS1 high vs. low patients indicated that FEZF1-AS1 regulates gene sets mainly associated with cell cycle progression. Cyclin dependent kinase inhibitor (CKI) was an important cell cycle regulator and P21 was one of the most important downstream target genes of tumor suppressor P53. Next, to investigate whether these genes could be regulated by FEZF1-AS1 in gastric cancer cells, we subsequently detected mRNAs and proteins in AGS and SGC7901 cells with si- FEZF1-AS1 and MGC-803 cell with 
Table1 Correlation of the expression of FEZF1-AS1 with clinicopathologic features in gastric cancer

\begin{tabular}{|c|c|c|c|c|}
\hline \multirow[t]{2}{*}{ Characteristics } & \multirow[t]{2}{*}{ N (\%) } & \multicolumn{2}{|c|}{ FEZF1-AS1 ${ }^{a}$} & \multirow[t]{2}{*}{$p$-value } \\
\hline & & High & $\overline{\text { Low }}$ & \\
\hline Gender & & & & 0.528 \\
\hline Male & $51(62.20 \%)$ & 31 & 20 & \\
\hline Female & $31(37.80 \%)$ & 21 & 10 & \\
\hline Age & & & & 0.670 \\
\hline$\leq 65$ & $27(32.93 \%)$ & 18 & 9 & \\
\hline$>65$ & $55(67.07 \%)$ & 34 & 21 & \\
\hline Stage & & & & $0.023^{*}$ \\
\hline । & $9(10.97 \%)$ & 5 & 4 & \\
\hline$\|$ & $23(28.05 \%)$ & 10 & 13 & \\
\hline III & $50(60.98 \%)$ & 37 & 13 & \\
\hline Tumor size & & & & $0.010^{*}$ \\
\hline$\leq 5$ & 29(35.37\%) & 13 & 16 & \\
\hline$>5$ & $53(64.63 \%)$ & 39 & 14 & \\
\hline Defferation & & & & 0.482 \\
\hline Well & $37(45.12 \%)$ & 25 & 12 & \\
\hline Poorly & $45(54.88 \%)$ & 27 & 18 & \\
\hline \multicolumn{5}{|l|}{ Lauren type } \\
\hline Intestinal & $35(42.68 \%)$ & 20 & 15 & 0.312 \\
\hline Diffuse & $47(57.32 \%)$ & 32 & 15 & \\
\hline
\end{tabular}

${ }^{\mathrm{a}}$ Fold change(FC) (tumor tissues relative to normal tissues) Fold change is greater than or equal to 2.0 for high expression, and less than 2.0 for low expression

${ }^{*} P<0.05$ was considered significant (Mann-Whitney $\mathrm{U}$ test between 2 groups,Kruskal-Wallis $\mathrm{H}(\mathrm{K})$ test among 3 groups)

pcDNA-FEZF1-AS1. The results showed that p21expression was up-regulated by 2.54 fold and 2.07 fold compared with control cells $(\mathrm{P}<0.01$, Fig. $5 \mathrm{a}$ and $\mathrm{b})$. However, ectopic expression of FEZF1-AS1 downregulated P21 expression than pcDNA vector (Fig. 5c). Furthermore, Weston blot assays showed that protein levels of p21was significantly increased in SGC-7901and AGS cell with si-FEZF1-AS1 cells (Fig. 5d and e); however, erogenous FEZF1-AS1 expression decreased the protein levels of p21 than pcDNA vector (Fig. 5f). Next, we investigated the role of P21 in FEZF1-AS1 promoted proliferation. Weston blot assays showed that protein levels of CDK2/CDK4/CDK6 was significantly decreased in SGC-7901 with si-FEZF1-AS1 cells; however, co-transfect of si-FEZF1-AS1 and si-P21 partly reversed CDK2/CDK4/CDK6 expression than si-NC (Additional file: 4 Figure S3A). These data indicated that P21 was involved in FEZF1-AS1-regulated cell cycle, contributing to gastric cancer cells proliferation.

\section{FEZF1-AS1epigenetically silenced P21 transcription through LSD1-Mediated H3K4me2 demethylation}

To further explore the molecular mechanisms by which FEZF1-AS1 regulated P21 transcription, we used ENCODE Histone Modification Tracks embedded in UCSC Genome Browser and found H3K4me2 enrichment peaks in the P21 promoter region (Additional file 3: Figure S2B and 2D). Considering that mechanisms of lncRNAs largely depend on specific cell locations, we found FEZF1-AS1 RNA was mostly located in the nucleus versus the cytoplasm (Additional file 3: Fig S2C), thus suggesting FEZF1-AS1 may exert transcriptional regulation function. Next, we conducted RIP assays and RNA-pull down assays to examine FEZF1-AS1's binding protein. As shown in Fig. 6a, the endogenous FEZF1-AS1 was enriched in the anti-LSD1 RIP fraction in AGS and SGC-7901 cells. Differential protein LSD1was specifically precipitated by FEZF1-AS1 in RNA-pull-down assay (Fig. 6b). Lysine-specific demethylase 1 (LSD1), the first Lysine demethylase identified, which demethylates mono- and di-methylated residues of lysine-4 on histone $\mathrm{H} 3$ (H3K4me1, H3K4me2 orH3K9me1), and LSD1could promote neural stem cell proliferation [36]. To further explore the molecular mechanisms of FEZF1-AS1 regulating P21 through LSD1-Mediated demethylation. Next, we knocked down LSD1 by si-RNA in AGS and SGC-7901 cells, and demonstrated that mRNA and

Table 2 Transcription factor of promoter of FEZF1-AS1

\begin{tabular}{|c|c|c|c|c|c|}
\hline ModellD & Score & Relativescore & Start & End & predictedsitesequence \\
\hline MA0079.3 & 11.569 & 0.926691945898605 & 751 & 761 & GCTCCTCCCTT \\
\hline MA0079.3 & 11.472 & 0.925471574849174 & 1809 & 1819 & ТТСССТСССТС \\
\hline MA0079.3 & 11.472 & 0.925471574849174 & 1881 & 1891 & тТСССтСССТС \\
\hline MA0079.3 & 11.472 & 0.925471574849174 & 1913 & 1923 & ТТСССТСССТС \\
\hline MA0079.3 & 11.445 & 0.925131883938508 & 1905 & 1915 & СТСССТСССТС \\
\hline MA0079.3 & 11.445 & 0.925131883938508 & 1909 & 1919 & СТСССТСССТС \\
\hline MA0079.3 & 9.880 & 0.905442392264696 & 1798 & 1808 & GCTCCTCCTIT \\
\hline MA0079.3 & 9.783 & 0.904222021215265 & 1893 & 1903 & ттСССТССтТ \\
\hline MA0079.3 & 9.756 & 0.903882330304599 & 1877 & 1887 & стСССТССТтС \\
\hline MA0079.3 & 9.756 & 0.903882330304599 & 1901 & 1911 & стссстссттс \\
\hline
\end{tabular}




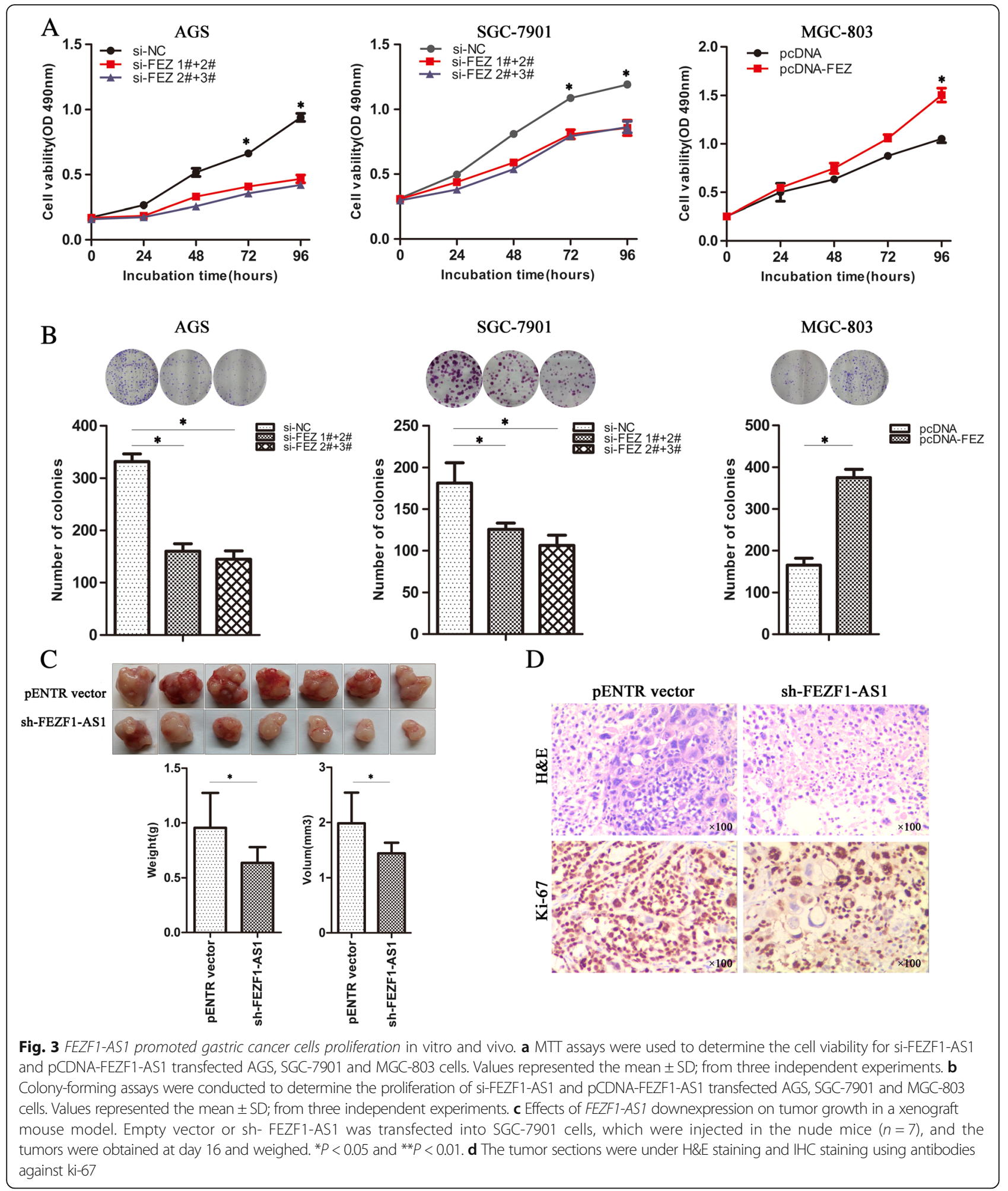

protein of P21 was upregulated compared to the controls (Fig. 6c and d); moreover, P21was enhanced in AGS and SGC-7901 cells treated with the LSD1inhibitor compared to untreated (Fig. 6e). Furthermore, co-transfect of pcDNA-FEZF1-AS1 and si-LSD1 partly reversed P21 expression than pcDNA vector (Additional file 4: Figure S3B). These results demonstrated that FEZF1-AS1 may directly bound with SD1 and possiblely regulated expression of P21 in the transcriptional level. Next, we used ChIP assays to verificate the mechanism. We analyzed the 

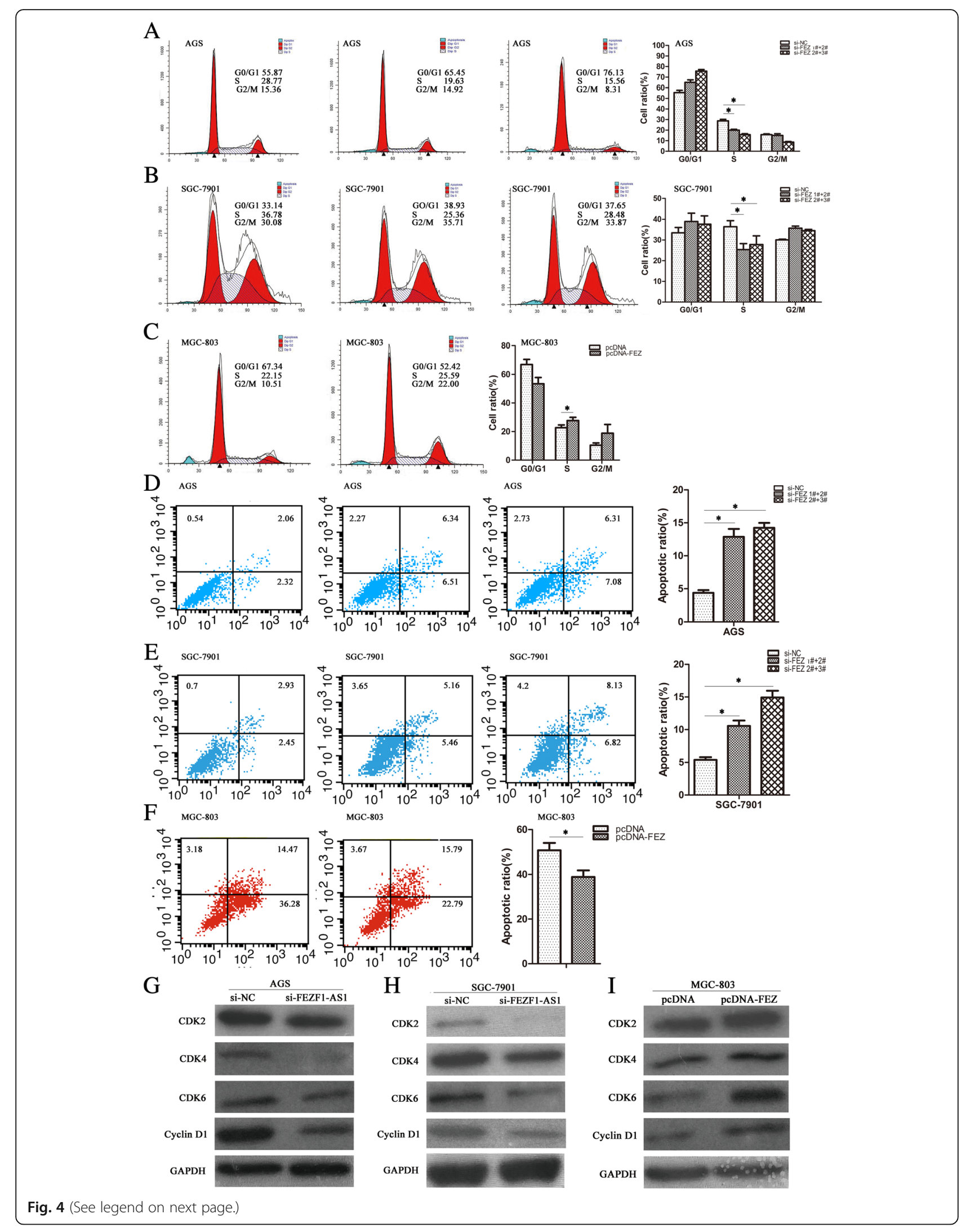
(See figure on previous page.)

Fig. 4 FEZF1-AS1 promoted proliferation of gastric cancer cells by inducing G1-S and reducing apoptosis in gastric cancer cells. $\mathbf{a}, \mathbf{b}$ and $\mathbf{c}$ The bar chart represented the percentage of AGS, SGC-7901 and MGC-803 cells in G0/G1, S or G2/M phase, as indicated. $\mathbf{d}$, e and $\mathbf{f}$ Flow cytometry was used to detect the apoptotic rates of cells. LR, early apoptotic cells; UR, terminal apoptotic cells. Values represented the mean $\pm S D$, from three independent experiments ${ }^{*} P<0.05,{ }^{*} P<0.01(\mathbf{g}, \mathbf{h}$ and i) Western blot analysis of CDK2, CDK4, CDK6 and CyclinD1 in AGS, SGC-7901 and MGC-803 cells with si-FEZF1-AS1 or pCDNA-FEZF1-AS1. GAPDH protein was used as an internal control

ChIP assays LSD1, dymethylation of histone $\mathrm{H} 3$ on lysine4(H3K4me1 and H3K4me2), markers which are associated with transcriptional regression on $\mathrm{P} 21$ promoter in presence of si-FEZF1-AS1. The results shown that LSD1 could directly bind to the promoter region of $P 21$ and mediate H3K4me2 modification, while knockdown of FEZF1-AS1 led to reduced LSD1 and increased H3K4me2 demethylation ability (Fig. $6 \mathrm{f}$ ); however, H3K4me1 was no change.

In conclusion, these data indicated that FEZF1-AS1 recruit the LSD1 to repress P21 transcription via H3K4me2 modification.

\section{Transcription factor SP1 was involved in the upregulation of FEZF1-AS1}

Relative expression levels of FEZF1-AS1 were overexpressed in gastric cancer cells compared to GES-1 cells. Then we explored the reason of overexpression of FEZF1-AS1. Abnormal of expression lncRNA are regulated by transcription factors and epigenetic modification, then we used the JASPAR software to analysis the promoter of FEZF1-AS1, which includes transcription factors SP-1 (Table 2). Next, we detected the expression of FEZF1-AS1 in gastric cancer cells with si-SP1, pcDNA-SP1 and control, the results shown that relative expression of FEZF1-AS1was downregulated in AGS and SGC-7901cells with si-SP1 (Fig. 7a); however, expression of FEZF1-AS1was upregulated in AGS and $293 \mathrm{~T}$ cells with pcDNA-SP1 compared with pcDNA vector (Fig. 7b). We used ChIP assays to determine that SP1 band to the endogenous FEZF1-AS1 promoter. The results of ChIP assays showed that SP1 could directly bind to FEZF1$A S 1$ promoter regions and induce FEZF1-AS1 transcription in AGS and SGC-7901 cells (Fig. 7c). Above results demonstrated overexpression of FEZF1-AS1 is mechanistically linked to increased gastric cancer cell proliferation via dependence on SP1. Finally, correlation analysis revealed that FEZF1-AS1expression levels were positive correlation with SP1 and CDK2/CDK4/CDK6/CyclinD1 and inversely correlated with P21 expression levels in Gastric Cancer tissues (Additional file 5: Figure S4). These results indicate that FEZF1-AS1 overexpression upregulated CDK2/CDK4/CDK6/CyclinD1expression by suppression P21 expression.

\section{Discussion}

Over the past decades, mounting evidences have emphasized the emerging significance of lncRNAs in diverse human cancer, including gastric cancer $[19,37,38]$.

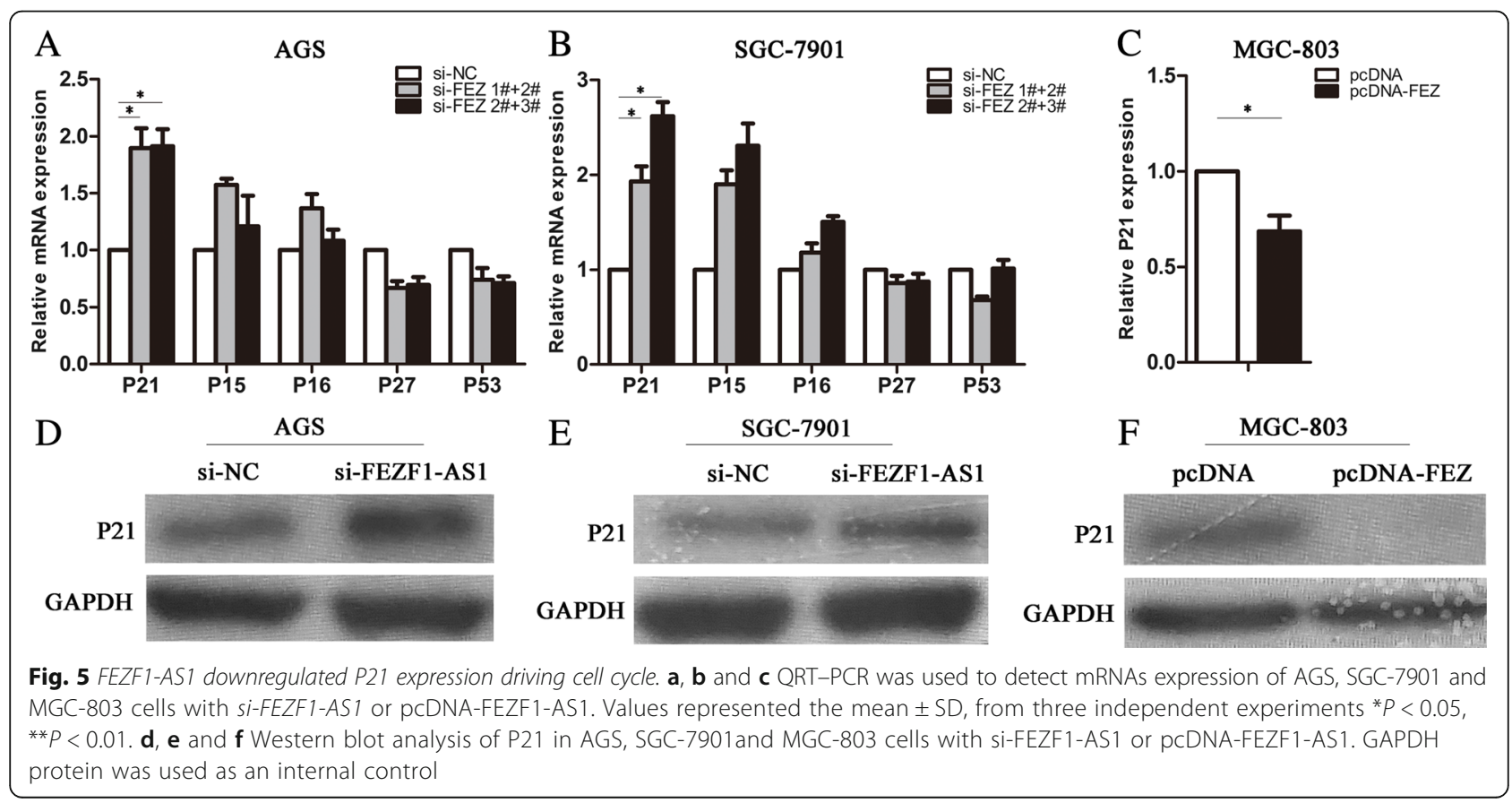




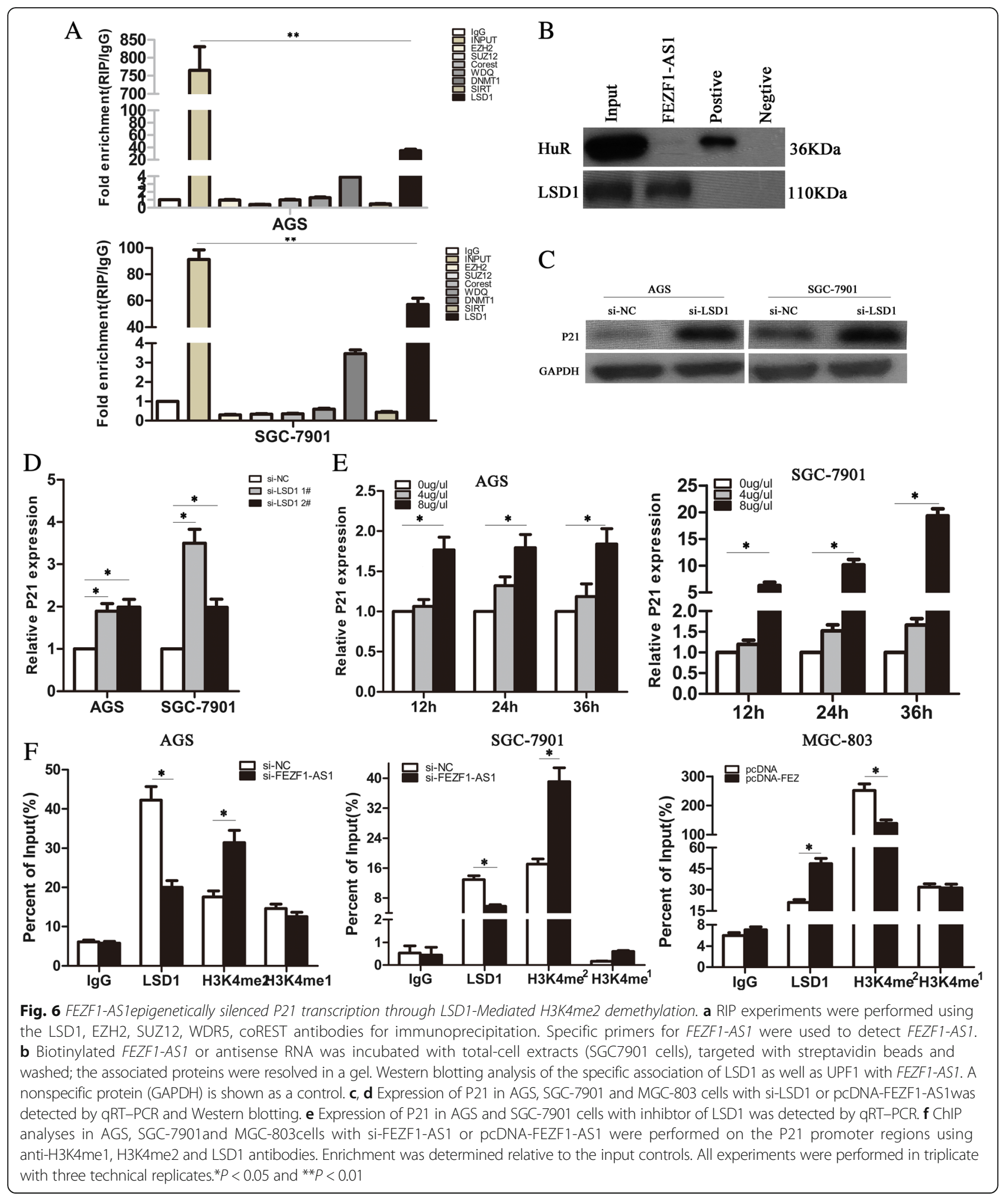

Forthrtmore, a small part of the study has shown that lncRNA expression profiles is predicting cancer or discriminating between cancer subtypes. In fact, lncRNAs have an obvious merit of their relative tissue-specific expression and functional layout as transcriptional levels. lncRNAs may better reflect the biologic status of cancer cells. However, lncRNAs in gastric cancer are still an emerging field, only a few of lncRNAs have been 


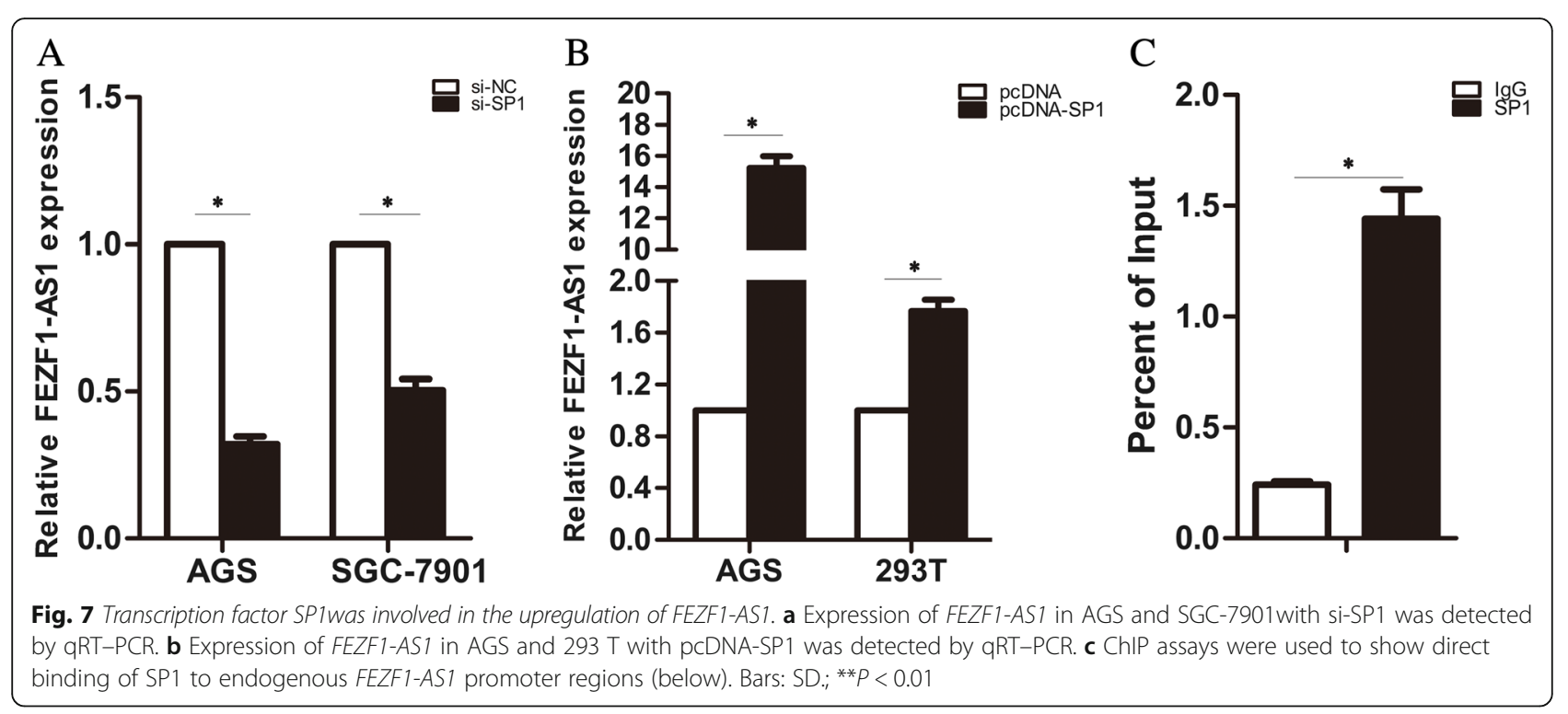

characterized in gastric cancer tumorigenesis and should be further studied as predictive biomarkers. One of these lncRNAs is gastric adenocarcinoma predictive long intergenic noncoding RNA (GAPLINC), GAPLINC is overexpression and a predictive marker for metastasis and prognosis in gastric cancer [39]. In this report, we found that the expression of another lncRNA, FEZF1-AS1, was significantly upregulated in gastric cancer tissues, and was correlated with poor prognosis. Furthermore, we have presented a study for the prediction of cancer/normal tissues and biomarkers using FEZF1-AS1 expression, suggesting that FEZF1-AS1 may be an independent clinical marker in gastric cancer diagnosis and prognosis.

The dysregulation of lncRNAs joins a wide variety of pathological processes, but the mechanisms of lncRNAs expression are not clear and further exploration is required. Transcription factor and epigenetic regulatory factors could manipulate the expression of lncRNAs [40, 41]. Here, through bioinformation analysis, we found that FEZF1-AS1promoter contained conserved SP1-binding site, which is a vital transcription factor in sustaining the "hall markers" of cancer [42]. Accumulating data has revealed that SP1 is overexpressed in breast cancer and gastric cancer [43, 44]. Our findings evidenced that SP1 is a key factor in controlling FEZF1-AS1 expression. These results, along with those recent studies $[45,46]$, underline the role of transcription factors in regulating lncRNA transcription.

Additionally, our data demonstrated that knockdown FEZF1-AS1expression contributed to significant inhibition of cell proliferation both in vitro and in vivo, whereas exogenous expression FEZF1-AS1 led to cell growth. Downregulation FEZF1-AS1 expression caused G1 phase arrest and $S$ phase reduction suppressing cell cycle progression. The $\mathrm{G} 1-\mathrm{S}$ transition in the cell cycle in mammalian cells is controlled by cyclins, cyclindependent kinases (CDKs) and their inhibitors, and the deregulation of CKIs is a common feature in tumor cells [47]. P21, one of the most CKIs, is important checkpoints of P53 signaling pathway for G1/S transition by inhibiting the activity of kinases such as CyclinD/CDK4, CyclinD/CDK6 and CyclinE/CDK2 $[48,49]$, which plays multiple roles in inhibition cell proliferation in normal and cancer cells and was almost downregulated in many types of cancer. Notably, we found that P21 was remarkably upregulated upon FEZF1-AS1 knockdown. Our findings demonstrated that FEZF1-AS1 mediated gastric cancer cell proliferation promotion, which possibly also downregulated p21 expression.

A small number of functional lncRNAs have been well characterized, which can regulate gene expression at various levels, including chromatin modification, transcription and post-transcriptional processing. lncRNAs can act as molecular decoys binding and titrating away proteins or RNAs to indirectly exert biological functions in multiple kingdoms of life. HOTAIR is one of the most studied lncRNAs involved in chromatin modification, which can recruit PRC2 genome-wide to alter H3K27 methylation and gene expression patterns. IncRNA MALAT1 could bind to SFPQ to release PTBP2 from the SFPQ/PTBP2 complex and increase SFPQ-detached PTBP2 promoting CRC cell proliferation and migration [50]. In addition, lncRNAs can recruit chromatinmodifying enzymes to target genes by acting as guides, either in cis (near the site of IncRNA production) [51] or in trans to distant target genes [52]. In this study, the results of RNA and RNA-pull-down assays show that FEZF1-AS1 could bind with LSD1, the first discovered histone demethylase. LSD1 participate in 
development and differentiation regulation of chromatin remodeling and histone demethylation, which could specifically catalysed the demethylation of mono- and di-methylated histone $\mathrm{H} 3$ lysine 4(H3K4) and H3 lysine 9 (H3K9) through a redox process. More importantly, overexpression of LSD1 is involved in many pathological processes of cancer, such as proliferation, apoptosis and metastasis of various cancer cells [26, 28, 34]. S. Lim et al. reported [34] that knockdown LSD1 significantly reduced levels of $\mathrm{H} 3 \mathrm{~K} 9 \mathrm{me} 2$ at the p21 locus regression cell proliferation through regulation of cell cycle. Our study demonstrated that knockdown FEZF1-AS1 led to enhance levels of $\mathrm{H} 3 \mathrm{~K} 4 \mathrm{me} 2$ at the p21 promoter and a nearly unchanged H3K4me1 levels.

\section{Conclusions}

In this study we had evidenced that FEZF1-AS1 was overexpressed in gastric cancer tissues; its overexpression may predict poor prognosis. FEZF1-AS1 promoted gastric cancer cell proliferation and tumorigenesis in vivio and vivo by affecting cell cycle progression. In addition, we described the molecular mechanism by which FEZF1-AS1 boost gastric cancer cell proliferation (Fig. 8) :(I) SP1 accelerated FEZF1-AS1overexpressioon in gastric cancer; (II) FEZF1 -AS1 caused G1-S arrest contributing to proliferation; (III) FEZF1 -AS1 repressed p21 transcription by recruiting LSD1 causing H3K4me2 demethylation at the p21 promoter in gastric cancer. Finally, these data provided new insights into the RNA

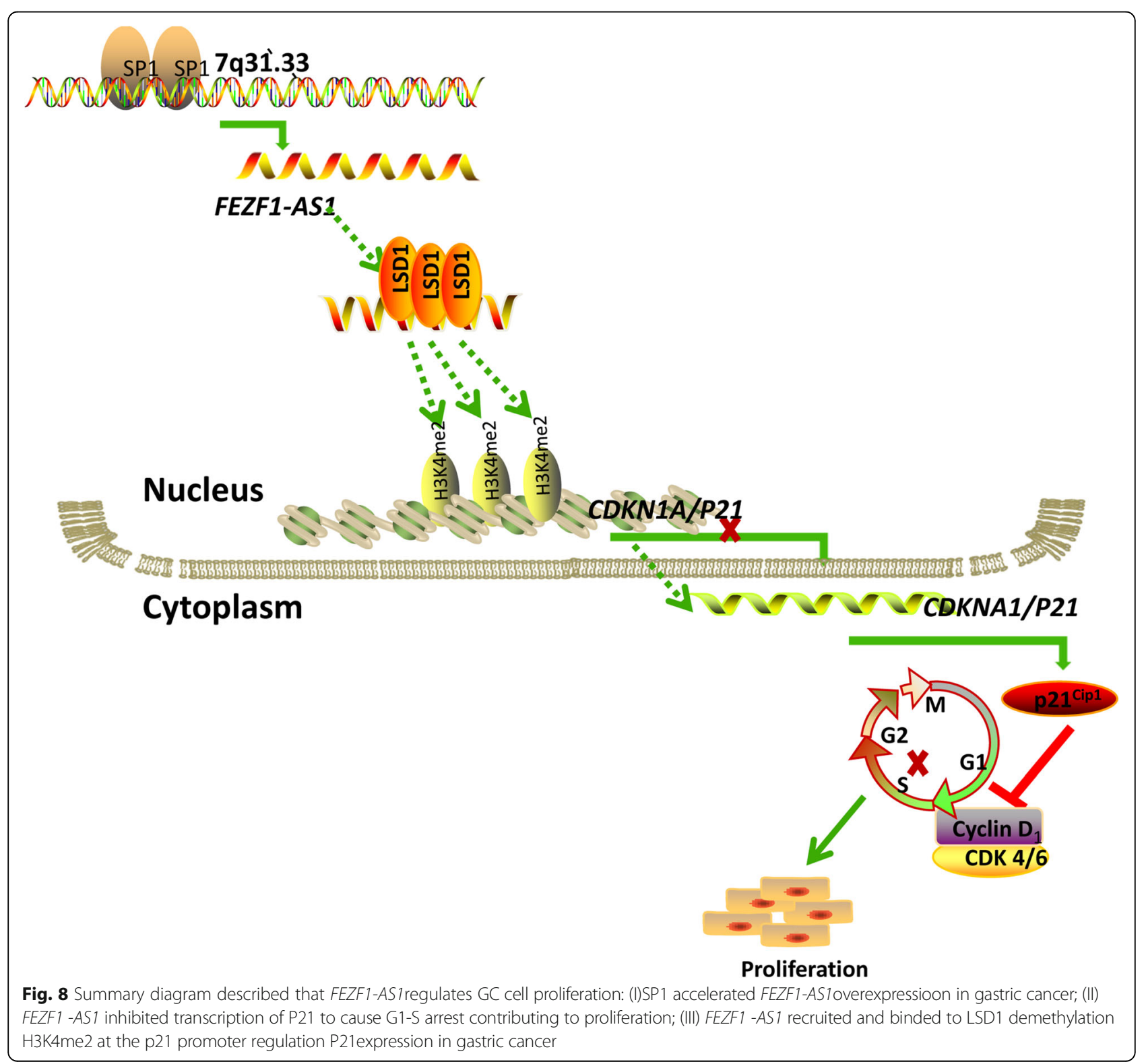


regulation network, indicating that lncRNAs could target chromatin-modifying enzymes regulating gene expression; LncRNAs have been proposed as potential targets for prognosis and therapeutic intervention.

\section{Additional files}

Additional file 1: Table S1. Primer sequences. (XLSX 8 kb)

Additional file 2: Figure S1. (A) The endogenous expression of FEZF1AS1 of gastric cancer cell lines (SGC-7901, MGC-803, BGC-823, AGS, HGC-27) and GES-1 cell. (B) QRT-PCR was used to detect FEZF1-AS1 expression of AGS, SGC-7901 and MGC-803cells with si-FEZF1-AS1 or pcDNA-FEZF1-AS1. (C) QRT-PCR was used to detect FEZF1-AS1 expression of SGC-7901 cells with sh- FEZF1-AS1. (D) QRT-PCR was used to detect SP1 expression of AGS, SGC-7901 and 293 T cells with si-SP1 or pcDNA-SP1. All experiments were performed in triplicate with three technical replicates. (TIF $915 \mathrm{~kb}$ )

Additional file 3: Figure S2. (A) The GSEA results showed enrichment of several genes that may be regulated by FEZF1-AS1. FEZF1-AS1 had significantly negative correlation with genes involved in cell cycle arrest in gastric cancer dataset(GSE15459). The barcode plot indicates the position of the genes in each gene set, and red and blue represent positive or negative Pearson's correlation with FEZF1-AS1 expression, respectively. (B) The RNA binding proteins with FEZF1-AS1 by GEO DataSet analysis. (C) Genome Browser and analyzed H3K4 enrichment peaks in the P21 promoter region. (D) FEZF1-AS1 expression levels in cell nucleus or cytoplasm of AGS, SGC-7901 and MGC-803 cells were detected by qRT-PCR. U6 was used as a nucleus marker and GAPDH was used as a cytosol marker. (TIF $7608 \mathrm{~kb}$ )

Additional file 4: Figure S3. (A) Proteins expression of CDK2/CDK4/ CDK6 in SGC-7901 cells with si-FEZF1-AS1 or si-P21 were detected by Western blotting. (B) Proteins expression of P21 in MGC-803 cells with si-LSD1 or pcDNA-FEZF1-AS1 were detected by Western blotting. (TIF $757 \mathrm{~kb}$ )

Additional file 5: Figure S4. The expressions of P21/SP-1/CDK2/CDK4/ CDK6/CyclinD1 and correlation with expressions of FEZF1-AS1 in 40 gastric cancer tissues (A) The expression of SP-1 was positive correlation with expressions of FEZF1-AS1 in 40 gastric cancer tissues $\left(R^{2}=0.197\right.$, $P=0.0042$ ). (B) The expression of $\mathrm{P} 21$ was negative correlation with expressions of FEZF1-AS1 in 40 gastric cancer tissues $\left(R^{2}=0.154, P=0.0124\right)$. (A) The expressions of CDK2/CDK4/CDK6/CyclinD1 were positive correlation with expressions of FEZF1-AS1 in 40 gastric cancer tissues, respectively $\left(R^{2}=0.111, P=0.0358 ; R^{2}=0.184, P=0.0058 ; R^{2}=0.144\right.$, $\left.P=0.0159 ; R^{2}=0.122, P=0.269\right)$. (TIF $504 \mathrm{~kb}$ )

\section{Abbreviations}

BSA: Bovine serum albumin; CDK: Cyclin-dependent kinase; CDK2: Cyclindependent kinase 2; CDK4: Cyclin-dependent kinase 4; CDK6: Cyclin-dependent kinase 6; ChIP: Chromatin immunoprecipitation; CKI: Cyclin dependent kinase inhibitor; CT: Cycle threshold; DFS: Disease-free survival; DMEM: Dulbecco's modified eagle medium; ECM: Extracellular matrix; EMT: Epithelial-tomesenchymal transition; EZH2: Enhancer of zest homolog 2; GAPDH: glyceraldehyde-3-phosphate dehydrogenase; GEO: Gene expression omnibus; GSEA: Gene set enrichment analysis; H3K27me3: Histone H3lysine-27 trimethylation; H3K4me1: Histone H3lysine-4 mono-methylation; H3K4me2: Histone H3lysine-4 di -methylation; H3K9me2: Histone H3lysine-9 di -methylation; HE: Hematoxylin and eosin; HOTAIR: HOX antisense intergenic RNA; IHC: Immunohistochemistry; LncRNA: Long non-coding RNA; LSD1: Lysinespecific demethylase 1; miR34a: microRNA34a; ncRNA: Non-coding RNA; PBS: Phosphate-buffered saline; PcG: Polycomb group protein; PMSF: Phenylmethanesulfonyl fluoride; PRC2: Polycomb repressive complex 2; PVDF: Polyvinylidene fluoride; qRT-PCR: Quantitative real-time polymerase chain reaction; RIP: RNA immunoprecipitation; ROC: Receiver operating characteristic; SDS-PAGE: Sodium dodecyl sulfate-polyacrylamide gel electrophoresis; ShRNA: Short hairpin RNA; SiRNA: Small interfering RNA; TBS: Tris-buffered saline; UICC: Union for international cancer control; WHO: the World Health Organization

\section{Acknowledgements}

We would like to thank Dr. Yongqian Shu for his hard work in preparing the clinical specimens.

\section{Funding}

This work was supported by grants from the National Natural Science Foundation of China (No.81271699; No. 31401094).

\section{Availability of data and materials}

Please contact the corresponding author for all data requests.

\section{Authors' contributions}

Conception and design: WD, CLW,GZJ. Development of the methodology: MX, FY. Acquisition of data: YWL, RX. Analysis and interpretation of data: MS, RX. Writing revision of the manuscript: YWL. Administrative, technical, and material support: KL, MX. Study supervision: WD, CLW and GZJ. All authors read and approved the final manuscript.

\section{Competing interests}

The authors declare that they have no competing interests.

\section{Consent for publication}

Not applicable.

\section{Ethics approval and consent to participate}

The research protocol was reviewed and approved by the Human Research Ethics Committee of Jiangsu Province People's Hospital, and written informed consent was obtained from each patient included in the study.

\section{Author details}

'Department of Oncology, Zhongda Hospital, Medical School, Southeast University, Nanjing, Jiangsu, People's Republic of China. ${ }^{2}$ Department of Laboratory, Affiliated Chest Hospital of southeast University, Nanjing, Jiangsu, People's Republic of China. ${ }^{3}$ Department of surgery, Affiliated the second hospital of Bengbu Medical College, Lianyungang, jiangsu, People's Republic of China. ${ }^{4}$ Department of Biochemistry and Molecular Biology, Nanjing Medical University, Nanjing, Jiangsu, People's Republic of China. ${ }^{5}$ Department of Gastroenterology Second Affiliated Hospital of Nanjing Medical University, Nanjing, Jiangsu, People's Republic of China.

Received: 18 July 2016 Accepted: 13 January 2017

Published online: 16 February 2017

\section{References}

1. Siegel R, Ma J, Zou Z, Jemal A. Cancer statistics, 2014. CA Cancer J Clin. 2014;64(1):9-29.

2. Orimo T, Nakano S, Inagaki M, Akabane H, Yanagida N, Shibaki T, Shomura H, Kudo T, Shonaka T, Oikawa F, Aiyama T. A case of AFP-producing gastric cancer patient with liver relapse occurred three months after endoscopic mucosal resection (EMR) and gastrectomy. Gan To Kagaku Ryoho. 2011;38(12):2328-30.

3. Hanahan D, Weinberg RA. Hallmarks of Cancer: The next generation. Cell. 2011;144(5):646-74.

4. Beaver JA, Amiri-Kordestani L, Charlab R, Chen W, Palmby T, Tilley A, Fourie ZJ, Yu J, Liu Q, Zhao L, Crich J, Chen XH, Hughes M, Bloomquist E, Tang S and Sridhara R, et al. FDA Approval: Palbociclib for the Treatment of Postmenopausal Patients with Estrogen Receptor-Positive, HER2-Negative Metastatic Breast Cancer. Clin Cancer Res. 2015;21(21):4760-6.

5. Parrish KE, Pokorny J, Mittapalli RK, Bakken K, Sarkaria JN and Elmquist WF. Efflux transporters at the blood-brain barrier limit delivery and efficacy of CDK4/6 inhibitor palbociclib (PD-0332991) in an orthotopic brain tumor model. J Pharmacol Exp Ther. 2015;355(2):264-71.

6. Mattick JS. The genetic signatures of noncoding RNAs. Plos Genet. 2009;5(4): e1000459.

7. Keller C, Kulasegaran-Shylini R, Shimada Y, Hotz HR, Buhler M. Noncoding RNAs prevent spreading of a repressive histone mark. Nat Struct Mol Biol. 2013;20(8):994-1000.

8. Lv J, Liu H, Huang Z, Su J, He H, Xiu Y, Zhang Y, Wu Q. Long non-coding RNA identification over mouse brain development by integrative modeling of chromatin and genomic features. Nucleic Acids Res. 2013;41 (22):10044-61. 
9. Diederichs TGAS. The hallmarks of cancer A long non-coding RNA point of view. Rna Biol. 2012;9(6):703-19. June 2012; @ 2012.

10. Tsai MC, Spitale RC, Chang HY. Long intergenic noncoding RNAs: new links in cancer progression. Cancer Res. 2011;71(1):3-7.

11. Spizzo R, Almeida Ml, Colombatti A, Calin GA. Long non-coding RNAs and cancer: a new frontier of translational research? Oncogene. 2012;31(43):4577-87.

12. Tang J, Lee J, Chang Y, Hou M, Huang H, Liaw C, Chang H. Long Noncoding RNAs-Related Diseases, Cancers, and Drugs. Sci World J. 2013;2013:1-7

13. Liu YW, Sun M, Xia R, Zhang EB, Liu XH, Zhang ZH, Xu TP, De W, Liu BR, Wang ZX. LincHOTAIR epigenetically silences miR34a by binding to PRC2 to promote the epithelial-to-mesenchymal transition in human gastric cancer. Cell Death Dis. 2015;6:e1802.

14. Kogo R, Shimamura T, Mimori K, Kawahara K, Imoto S, Sudo T, Tanaka F, Shibata K, Suzuki A, Komune S, Miyano S, Mori M. Long Noncoding RNA HOTAIR Regulates Polycomb-Dependent Chromatin Modification and Is Associated with Poor Prognosis in Colorectal Cancers. Cancer Res. 2011;71(20):6320-6.

15. Gupta RA, Shah N, Wang KC, Kim J, Horlings HM, Wong DJ, Tsai M, Hung T, Argani P, Rinn JL, Wang Y, Brzoska P, Kong B, Li R, West RB, van de Vijver $\mathrm{MJ}$, et al. Long non-coding RNA HOTAIR reprograms chromatin state to promote cancer metastasis. Nature. 2010;464(7291):1071-6.

16. Kim IJGC K. HOTAIR is a negative prognostic factor and exhibits prooncogenic activity in pancreatic cancer. Oncogene. 2012;2012:1-10.

17. Tsang WP, Kwok TT. Riboregulator H19 induction of MDR1-associated drug resistance in human hepatocellular carcinoma cells. Oncogene. 2007; 26(33):4877-81.

18. Cao WJ, Wu HL, He BS, Zhang YS, Zhang ZY. Analysis of long non-coding RNA expression profiles in gastric cancer. World J Gastroenterol. 2013; 19(23):3658-64.

19. Xu TP, Liu XX, Xia R, Yin L, Kong R, Chen WM, Huang MD and Shu YQ. SP1induced upregulation of the long noncoding RNA TINCR regulates cell proliferation and apoptosis by affecting KLF2 mRNA stability in gastric cancer. Oncogene. 2015;34(45):5648-61.

20. Zhang EB, Kong R, Yin DD, You LH, Sun M, Han L, Xu TP, Xia R, Yang JS, De W, Chen J. Long noncoding RNA ANRIL indicates a poor prognosis of gastric cancer and promotes tumor growth by epigenetically silencing of miR-99a/miR-449a. Oncotarget. 2014;5(8):2276-92.

21. Guil S, Esteller M. Cis-acting noncoding RNAs: friends and foes. Nat Struct Mol Biol. 2012:19(11):1068-75

22. Kerin T, Ramanathan A, Rivas K, Grepo N. Coetzee GA and Campbell DB. A noncoding RNA antisense to moesin at 5p14.1 in autism. Sci Transl Med. 2012;4(128):128r-40r.

23. Silveira RA, Fachel AA, Moreira YB, De Souza CA, Costa FF, Verjovski-Almeida $\mathrm{S}$, Pagnano KBB. Protein-coding genes and long noncoding RNAs are differentially expressed in dasatinib-treated chronic myeloid leukemia patients with resistance to imatinib. Hematology. 2014;19(1):31-41.

24. Kotake Y, Nakagawa T, Kitagawa K, Suzuki S, Liu N, Kitagawa M, Xiong Y. Long non-coding RNA ANRIL is required for the PRC2 recruitment to and silencing of p15(INK4B) tumor suppressor gene. Oncogene. 2011;30(16): 1956-62.

25. Shi Y, Lan F, Matson C, Mulligan P, Whetstine JR, Cole PA, Casero RA, Shi Y. Histone demethylation mediated by the nuclear amine oxidase homolog LSD1. Cell. 2004;119(7):941-53.

26. Metzger E, Wissmann M, Yin N, Müller JM, Schneider R, Peters AHFM, Günther T, Buettner R, Schüle R. LSD1 demethylates repressive histone marks to promote androgen-receptor-dependent transcription. Nature. 2005;437(7057):436-9.

27. Laurent B, Ruitu L, Murn J, Hempel K, Ferrao R, Xiang Y, Liu S, Garcia BA, Wu H, Wu F, Steen H, Shi Y. A Specific LSD1/KDM1A Isoform Regulates Neuronal Differentiation through H3K9 Demethylation. Mol Cell. 2015;57(6):957-70,

28. Hayami S, Kelly JD, Cho HS, Yoshimatsu M, Unoki M, Tsunoda T, Field HI, Neal DE, Yamaue H, Ponder BA, Nakamura Y, Hamamoto R. Overexpression of LSD1 contributes to human carcinogenesis through chromatin regulation in various cancers. Int J Cancer. 2011;128(3):574-86.

29. Schulte JH, Lim S, Schramm A, Friedrichs N, Koster J, Versteeg R, Ora I, Paitler K, Klein-Hitpass L, Kuhfittig-Kulle S, Metzger E, Schule R, Eggert A, Buettner R, Kirfel J. Lysine-specific demethylase 1 is strongly expressed in poorly differentiated neuroblastoma: implications for therapy. Cancer Res. 2009;69(5):2065-71.
30. Wang J, Scully K, Zhu X, Cai L, Zhang J, Prefontaine GG, Krones A, Ohgi KA, Zhu P, Garcia-Bassets I, Liu F, Taylor H, Lozach J, Jayes FL, Korach KS, Glass CK, et al. Opposing LSD1 complexes function in developmental gene activation and repression programmes. Nature. 2007:446(7138):882-7.

31. Kahl P, Gullotti L, Heukamp LC, Wolf S, Friedrichs N, Vorreuther R, Solleder G, Bastian PJ, Ellinger J, Metzger E, Schule R, Buettner R. Androgen receptor coactivators lysine-specific histone demethylase 1 and four and a half LIM domain protein 2 predict risk of prostate cancer recurrence. Cancer Res. 2006;66(23):11341-7.

32. Huang $Y$, Vasilatos SN, Boric L, Shaw PG, Davidson NE. Inhibitors of histone demethylation and histone deacetylation cooperate in regulating gene expression and inhibiting growth in human breast cancer cells. Breast Cancer Res Treat. 2012;131(3):777-89.

33. Willmann D, Lim S, Wetzel S, Metzger E, Jandausch A, Wilk W, Jung M, Forne I, Imhof A, Janzer A, Kirfel J, Waldmann H, Schule R, Buettner R. Impairment of prostate cancer cell growth by a selective and reversible lysine-specific demethylase 1 inhibitor. Int J Cancer. 2012;131(11):2704-9.

34. Lim S, Janzer A, Becker A, Zimmer A, Schule R, Buettner R, Kirfel J. Lysine-specific demethylase 1 (LSD1) is highly expressed in ER-negative breast cancers and a biomarker predicting aggressive biology. Carcinogenesis. 2010;31 (3):512-20.

35. Song W, Liu Y, Peng J, Liang H, Chen H, Chen J, He W, Xu J, Cai S, He Y. Identification of differentially expressed signatures of long non-coding RNAs associated with different metastatic potentials in gastric cancer. J Gastroenterol. 2016;51(2):119-29.

36. Sun G, Alzayady K, Stewart R, Ye P, Yang S, Li W, Shi Y. Histone Demethylase LSD1 Regulates Neural Stem Cell Proliferation. Mol Cell Biol. 2010;30(8): 1997-2005.

37. Yuan SX, Wang J, Yang F, Tao QF, Zhang J, Wang LL, Yang Y, Liu H, Wang ZG, Xu QG, Fan J, Liu L, Sun SH, Zhou WP. Long noncoding RNA DANCR increases stemness features of hepatocellular carcinoma by derepression of CTNNB1. Hepatology. 2016;63(2):499-511.

38. Yuan S, Wang J, Yang F, Tao Q, Zhang J, Wang L, Yang Y, Liu H, Wang Z, XU Q, Fan J, Liu L, Sun S and Zhou W. Long noncoding RNADANCR increases stemness features of hepatocellular carcinoma via de-repression ofCTNNB1. HEPATOLOGY. 2015:n/a-n/a.

39. Hu Y, Wang J, Qian J, Kong X, Tang J, Wang Y, Chen H, Hong J, Zou W, Chen Y, XU J, Fang JY. Long Noncoding RNA GAPLINC Regulates CD44Dependent Cell Invasiveness and Associates with Poor Prognosis of Gastric Cancer. Cancer Res. 2014:74(23):6890-902.

40. Zhang EB, Yin DD, Sun M, Kong R, Liu XH, You LH, Han L, Xia R, Wang KM Yang JS, De W, Shu YQ, Wang ZX. P53-regulated long non-coding RNA TUG1 affects cell proliferation in human non-small cell lung cancer, partly through epigenetically regulating HOXB7 expression. Cell Death Dis. 2014:5:e1243.

41. Sun $M$, Liu XH, Wang KM, Nie FQ, Kong R, Yang JS, Xia R, Xu TP, Jin FY, Liu ZJ, Chen JF, Zhang EB, De W, Wang ZX. Downregulation of BRAF activated non-coding RNA is associated with poor prognosis for non-small cell lung cancer and promotes metastasis by affecting epithelial-mesenchymal transition. Mol Cancer. 2014;13:68.

42. Beishline KAC. Sp1 and the 'hallmarks of cancer'. FEBS J. 2015;282(2):224-58.

43. Wang L, Wei D, Huang S, Peng Z, Le X, Wu TT, Yao J, Ajani J, Xie K. Transcription factor Sp1 expression is a significant predictor of survival in human gastric cancer. Clin Cancer Res. 2003;9(17):6371-80.

44. Wang XB, Peng WQ, Yi ZJ, Zhu SL, Gan QH. Expression and prognostic value of transcriptional factor sp1 in breast cancer. Ai Zheng. 2007;26(9):996-1000.

45. Ma MZ, Li CX, Zhang Y, Weng MZ, Zhang MD, Qin YY, Gong W, Quan ZW. Long non-coding RNA HOTAIR, a c-Myc activated driver of malignancy, negatively regulates miRNA-130a in gallbladder cancer. Mol Cancer. 2014;13:156.

46. Wan G, Mathur R, Hu X, Liu Y, Zhang X, Peng G, Lu X. Long non-coding RNA ANRIL (CDKN2B-AS) is induced by the ATM-E2F1 signaling pathway. Cell Signal. 2013;25(5):1086-95.

47. Sherr CJ1, Roberts JM. Inhibitors of mammalian G1 cyclin-dependent kinases. Genes Dev. 1995;9(10):1149-63.

48. Gartel AL1, Radhakrishnan SK. Lost in transcription: p21 repression, mechanisms, and consequences. Cancer Res. 2005;65(10):3980-5.

49. Sherr CJ, Roberts JM. CDK inhibitors: positive and negative regulators of G1-phase progression. Genes Dev. 1999;13(12):1501-12.

50. Ji Q, Zhang L, Liu X, Zhou L, Wang W, Han Z, Sui H, Tang Y, Wang Y, Liu N, Ren J, Hou F, Li Q. Long non-coding RNA MALAT1 promotes tumour 
growth and metastasis in colorectal cancer through binding to SFPQ and releasing oncogene PTBP2 from SFPQ/PTBP2 complex. Brit J Cancer. 2014;111(4):736-48.

51. Wang KC, Yang YW, Liu B, Sanyal A, Corces-Zimmerman R, Chen Y, Lajoie BR, Protacio A, Flynn RA, Gupta RA, Wysocka J, Lei M, Dekker J, Helms JA, Chang HY. A long noncoding RNA maintains active chromatin to coordinate homeotic gene expression. Nature. 2011;472(7341):120-4.

52. Huarte M, Guttman M, Feldser D, Garber M, Koziol MJ, Kenzelmann-Broz D, Khalil AM, Zuk O, Amit I, Rabani M, Attardi LD, Regev A, Lander ES, Jacks T, Rinn JL. A large intergenic noncoding RNA induced by p53 mediates global gene repression in the p53 response. Cell. 2010;142(3):409-19.

Submit your next manuscript to BioMed Central and we will help you at every step:

- We accept pre-submission inquiries

- Our selector tool helps you to find the most relevant journal

- We provide round the clock customer support

- Convenient online submission

- Thorough peer review

- Inclusion in PubMed and all major indexing services

- Maximum visibility for your research

Submit your manuscript at www.biomedcentral.com/submit
Biomed Central 